\title{
Influence of environmental parameters on the distribution of subfossil chironomids in surface sediments of Bosten lake (Xinjiang, China)
}

\author{
Enlou ZHANG,${ }^{1 *}$ Boying ZHENG,${ }^{1,2}$ Yanmin CAO,${ }^{1,2}$ Guang GAO,${ }^{1}$ Ji SHEN $^{1}$ \\ ${ }^{1}$ State Key Laboratory of Lake Science and Environment, Nanjing Institute of Geography and Limnology, Chinese Academy of \\ Sciences, Nanjing 210008, P.R. China; ${ }^{2}$ Graduate School of the Chinese Academy of Sciences, Beijing 100049, P.R. China \\ *Corresponding author: elzhang@niglas.ac.cn
}

\begin{abstract}
The distribution of larval subfossil chironomids in surface sediment samples obtained from Bosten lake was analysed, and ordination methods were used to identify the influences of physical and chemical parameters on the abundance and diversity of chironomids. A total of 18 chironomid taxa was identified across the 32 samples, 15 of which showed minimum abundance of $>1 \%$ and were present in more than one site. Chironomus plumosus-type, Microchironomus and Tanytarsus glabrescens-type were the most abundant of the 18 chironomid taxa identified. The distribution of the main chironomid species within Bosten Lake exhibited spatial heterogeneity. T. glabrescens-type was found to dominate Huangshuiwan, in the northwest part of Bosten lake, which had higher salinity and organic content. Microchironomus was mainly distributed in the Kaidu river mouth, in the southwest part of Bosten lake, whereas C. plumosus-type was more abundant in the deep centre, suggesting the importance of water chemistry, water dynamics and water depth on chironomid distribution. The relationship of chironomid distribution with environmental parameters was assessed using redundancy analysis, and the results revealed that water depth, Secchi depth and salinity were the predominant factors influencing chironomid distribution; these factors could explain the chironomid variances of 18.3, 5.3 and 5.0\%, respectively. Our surface sediment-derived data provide a baseline for the analysis of future environmental variations of the lakes in the arid regions of northwest China, which are threatened by impacts of global climate change and regional water management.
\end{abstract}

Key words: subfossil chironomid, Bosten lake, numerical analyses, environmental variables.

Received: March 2012. Accepted: May 2012.

\section{INTRODUCTION}

Non-biting aquatic midges (Chironomidae: Diptera) are considered to be ideal organisms for bioassays as they are abundant and widespread in freshwater ecosystems, and many of them are stenotopic and sensitive to environmental changes around them (Cranston, 1995). In lentic environments, the analysis of benthic fauna, particularly Chironomidae, has played a dominant role in water quality assessment (Saether, 1979). Chironomids are sensitive to environmental change and the larval head capsules are often well preserved in lake sediments. In addition to their well-known applications in bio-monitoring, subfossil chironomids are ideal indicators of past environmental changes in lentic ecosystems (Walker, 2001), since subfossil chironomid larvae are relatively easy to identify. Chironomids colonise a range of habitats within large lakes, and their distribution is inherently variable across spatial and temporal scales (Eggermont et al., 2007).

Previous studies on the intra-lake distribution of chironomid assemblages suggest that understanding patterns related to the intra-lake distribution of fossil remains may improve the quality of environmental reconstruction, and demonstrate that several factors such as water temperature, substrate, food availability, hypolimnetic oxygen, windinduced currents and distribution of aquatic macrophytes vary as a function of water depth, considerably influencing the chironomid distribution within lakes (Frey, 1988; Heiri et al., 2003; Eggermont et al., 2007; Kurek and Cwynar, 2009; Holmes et al., 2009; Engels and Cwynar, 2011). Although there is appreciable potential to reconstruct environmental change using subfossil chironomids in China (Zhang et al., 2006, 2007, 2010, 2011), the subfossil and living chironomids in arid central Asia are poorly known, as relatively few studies have dealt with the midges from this vast region. Therefore, studies of chironomid distribution and ecology in this region will serve as sensitive indicators of recent environmental change.

Bosten lake is located in the arid continental region of central Asia in Xinjiang, and is the largest inland freshwater lake in China. It plays an important role in ecosystem service and is an important natural resource for the development of the surrounding region, because it provides freshwater supply for industry and human consumption, offers biotic resources and serves as an emergency water diversion to the Tarim river (Jin et al., 2002). However, in recent decades Bosten lake has been subjected to human impact and threatened by environmental changes, resulting in a trend of eutrophication and salination (Liu and Zhang, 1998; Xu et al., 2003; Zhang and $\mathrm{Hu}, 2008$ ). The present study investigates the distribution of the sub- 
fossil chironomid assemblage in the surface sediment of Bosten lake, to determine the influence of physical and chemical parameters on the abundance and diversity of chironomids in the lake. The surface sediment incorporates the remains of midges deposited over the past few years. The distribution of chironomids in surface sediments has been widely used as a means of determining the spatial variability of living chironomid fauna (Walker et al., 1984; Frey, 1988). Moreover, the taxonomic resolution of chironomid fossils found in surface sediments is equivalent to remains preserved in sediment cores. Thus, the relationships identified between surface chironomid assemblages and environmental variables can be directly applied to the interpretation of palaeo-chironomid data (Langdon et al., 2010).

This paper aims to present the first record of the chironomids of Bosten lake, identify within lake variability of chironomid assemblages and determine which environmental factors influence the distribution of chironomid assemblages within it, which will aid the interpretation of palaeolimnological data sets for reconstructing past trends and inferring the magnitude of environmental change over a range of timescales.

\section{METHODS}

\section{Study site}

Bosten lake $\left(86^{\circ} 40^{\prime}-87^{\circ} 26^{\prime} \mathrm{E}, 41^{\circ} 56^{\prime}-42^{\circ} 14^{\prime} \mathrm{N}\right)$ is located in Yanqi basin in Southern Xinjiang, Northwest China (Fig. 1). It is the largest inland freshwater lake in China with a surface area of $1048.5 \mathrm{~km}^{2}$, with a maximum depth of $17 \mathrm{~m}$ and a mean depth of $7.5 \mathrm{~m}$ (Wang and Dou, 1998). The lake is influenced by a temperate continental climate. The mean annual air temperature is approximately $8.3^{\circ} \mathrm{C}$, the mean annual precipitation is approximately $65 \mathrm{~mm}$ and the mean annual evaporation is approximately $1881 \mathrm{~mm}$. The lake is mainly fed by the Kaidu river and some other seasonal rivers, and it drains into Konqi river and eventually into Lop Nur (Wang and Dou, 1998).

\section{Sample collection and laboratory treatment}

In August 2010, 32 surface-sediment samples were collected from Bosten lake with the aid of a Kajak gravity corer (Fig. 1). The uppermost 1-cm sediments of each core were extruded in the field, and the samples were refrigerated at $4{ }^{\circ} \mathrm{C}$ until further analysis. The Secchi depth, water depth, surface and bottom water temperature, conductivity, salinity, $\mathrm{pH}$, turbidity, chlorophyll a ( $\mathrm{Chl} a$ ) and dissolved oxygen (DO) were measured at each site in the field using a multi-parameter underwater sensor (YSI 6600, Yellow Springs Instruments, Inc., Yellow Springs, $\mathrm{OH}, \mathrm{USA})$. The chemical oxygen demand $\left(\mathrm{COD}_{\mathrm{Mn}}\right)$, total phosphorus (TP), total nitrogen (TN), $\mathrm{NH}_{4} \mathrm{~N}$, total or- ganic carbon (TOC), $\mathrm{NO}_{3}{ }^{-} \mathrm{N}, \mathrm{SO}_{4}{ }^{2-}$ and $\mathrm{Cl}^{-}$in the water column were measured in the laboratory using Water and Wastewater Monitoring Methods (2002). The sediments in the northeast corner of the lake were mainly composed of sand fraction and no surface sediment samples were extracted. However, the water was sampled and corresponding parameters were measured. The presence/absence of macrophytes at each core site was recorded as a dummy variable.

The sediment samples were processed for chironomid analysis according to standard techniques (Brooks et al., 2007). Wet sediment samples were deflocculated in $10 \%$ $\mathrm{KOH}$ in a $75^{\circ} \mathrm{C}$ water bath for $15 \mathrm{~min}$, and rinsed on 212 and $90-\mu \mathrm{m}$ sieves. The residue was transferred to a grooved perspex sorting tray, and chironomid larval head capsules were picked from the sediments using fine forceps under a stereo-zoom microscope at $25 \times$. A minimum of 50 identifiable whole head capsules are expected for each sample to be representative (Heiri and Lotter, 2001; Larocque et al., 2001; Quinlan and Smol, 2001). The head capsules were permanently mounted ventral side facing up on slides using Hydromatrix ${ }^{\circledR}$, and subsequently identified at $100-400 \times$ magnification according to the taxonomy of Brooks et al. (2007), with reference to Wiederholm (1983), Oliver and Roussel (1983), and Rieradevall and Brooks (2001).

\section{Numerical and statistical analyses}

Gradient analysis was calculated on selected taxa, which occurred at least twice, and percentage abundance exceeded $2 \%$. The environmental variables were $\log _{10}$ $(\mathrm{x}+1)$ transformed prior to ordination analysis. Detrended correspondence analysis (DCA) (ter Braak and Pretice, 1988) showed that the compositional length of the envi-

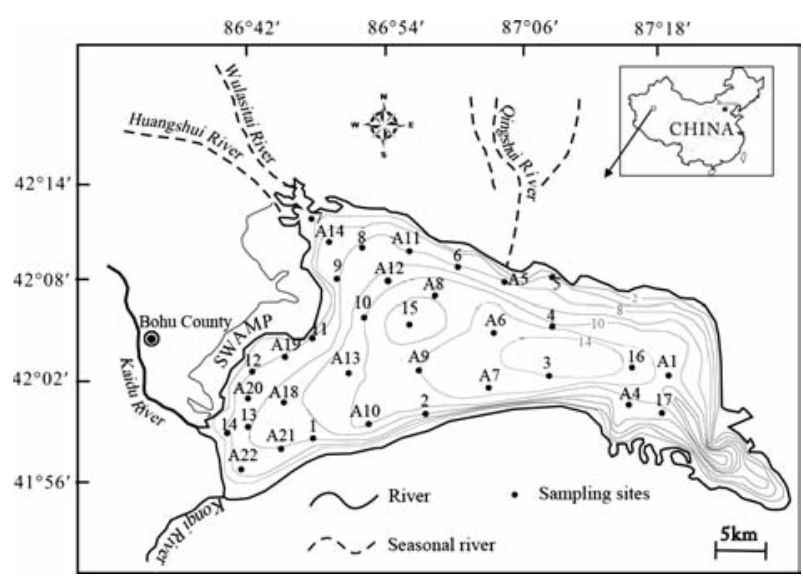

Fig. 1. Location of Bosten lake in Northwest China (isobars after Chen et al., 2006) and location of sampling sites. 
ronmental gradient was less than 2 standard deviations. Therefore, linear ordination method (redundancy analysis, RDA) was suitable for assessing the impact of the environmental variables on chironomid community distribution. Automatic forward selection was used to identify a minimum subset of significant explanatory variables. Monte Carlo permutation tests ( $n=999$ unrestricted permutations) were used to test the significance of each variable. Collinearity among variables were assessed via variance inflation factors (VIFs), which were examined by a series of RDAs on all the significant variables, and variables with high VIFs ( $>20$ ) were excluded from further analysis (Hall et al., 1999). Partial RDAs was also performed to calculate variance in chironomid data explained by the unique effects of each of the forward-selected variables using variance partitioning analysis. The explanatory proportions of all the environmental variables were also quantified. The ordination analyses were based on square-root transformed percentage data with downweighing of rare taxa while the presence/absence of macrophytes was coded as a $1 / 0$ dummy variable. The analyses were undertaken using CANOCO version 4.5 (ter Braak and Šmilauer, 2002).

\section{RESULTS}

\section{Environmental parameters}

The measured physical and chemical parameters of lake water and sediment are summarised in Tab. 1 and Fig. 2. The mean water depth at the sampling locations ranged from 1.5-14 $\mathrm{m}$ (mean depth: $6.3 \mathrm{~m}$ ) (Fig. 1). The lake water is alkaline, with $\mathrm{pH}$ values ranging from 8.9 to 9.3. The salinity ranged from $0.19-1.48 \mathrm{~g} \cdot \mathrm{L}^{-1}$, and the conductivity ranged from $376-2865 \mu \mathrm{S} \cdot \mathrm{cm}^{-1}$. Relatively low salinity values were measured predominantly in sites near the Kaidu river mouth as well as a north-south salinity gradient (Fig. 2), indicating that the freshwater diverted from the Kaidu river plays a significant role in maintaining the existing salinity level of Bosten lake.

\section{Distribution of subfossil chironomid within Bosten lake}

A total of 2912 midge subfossils was sorted, and 18 taxa were identified (Fig. 3). Most chironomid head capsules were identified to species level, while other capsules were identified to the genus level or to species or genus groups because of the fragmented subfossils or imperfection of integrated taxonomy. The chironomid distribution was dominated by Chironomus plumosus-type, Microchironomus and Tanytarsus (mainly Tanytarsus glabrescenstype). Spatial distribution of the fauna revealed obvious differences in the species abundance across the sampling sites. T. glabrescens-type species was found to dominate the Huangshuiwan area, northwest of Bosten lake. Microchironomus species was mainly distributed in the Kaidu river mouth, and C. plumosus-type fossils were abundant in the deep regions of Bosten lake (Fig. 4).

Other species and genera such as Cladotanytarsus mancus-type, Cricotopus sylvestris-type, Glyptotendipes barbipes-type, Limnophyes, Polypedilum nubifer-type and Psectrocladius sordidellus-type were mainly restricted to relatively shallow areas where the water depth was less than $7 \mathrm{~m}$. Procladius and Cladopelma lateralistype were evenly distributed throughout the lake with no spatial heterogeneity.

\section{Ordination analysis}

The DCA ordination showed the compositional length of the environmental gradient was 1.769 (standard deviation), indicating that RDA is suitable for ordination analysis. Automatic forward selection suggests that the water depth (WD), Secchi depth and salinity comprise the minimum subset of significant environmental factors $(\mathrm{P}<0.05)$, explaining $43.2 \%$ of the cumulative chironomid variances with all the VIFs $<20$ (Fig. 5). Various partitioning analysis revealed that $18.9,5.3$ and $5.0 \%$ variance of chironomid fauna are influenced solely by water depth, Secchi depth and salinity, respectively.

Tab. 1. Results of selected physical-chemical parameters of water and sediments at sampling sites in Bosten lake.

\begin{tabular}{|c|c|c|c|}
\hline Parameters & Mean & Minimum & Maximum \\
\hline Water depth (m) & 1.5 & 14 & 6.3 \\
\hline Secchi depth (m) & 2.3 & 0.5 & 3.6 \\
\hline Salinity $\left(\mathrm{g} / \mathrm{L}^{-1}\right)$ & 1.04 & 0.19 & 1.48 \\
\hline Conductivity $\left(\mu \mathrm{S} \mathrm{cm}^{-1}\right)$ & 2061 & 376 & 2865 \\
\hline $\mathrm{pH}$ & 9.2 & 8.9 & 9.3 \\
\hline Bottom dissolved oxygen $\left(\mathrm{mg} \mathrm{L}^{-1}\right)$ & 6.86 & 1.37 & 9.01 \\
\hline Total phosphorus $\left(\mu \mathrm{g} \mathrm{L}^{-1}\right)$ & 24.3 & 5 & 73 \\
\hline Total nitrogen $\left(\mathrm{mg} \mathrm{L}^{-1}\right)$ & 1.01 & 0.31 & 1.53 \\
\hline Chlorophyll-a (mg L-1) & 2.59 & 1.30 & 5.35 \\
\hline Median grain size $(\mu \mathrm{m})$ & 12.784 & 7.244 & 18.152 \\
\hline Loss on ignition $(\%)$ & 10.21 & 3.57 & 15.33 \\
\hline
\end{tabular}




\section{DISCUSSION}

From Fig. 4, spatial heterogeneity is evident in the distribution of the main chironomid taxa in Bosten lake. T. glabrescens-type was mainly distributed in the northwest area of Bosten lake (also called Huangshuiwan), where the lake water has highest salinity and nutrient levels as a result of the industrial and agricultural sewage drained into Huangshuiwan in recent years, increasing the pollution levels in the lake (Liu and Zhang, 1998; Xu et al., 2003; Zhang and $\mathrm{Hu}, 2008$ ). When the sedimentation process was stabilised, Tanytarsini species, which are small-sized collector-feeders, can adapt to new habitats rapidly (Tronstad et al., 2007), these organisms were present at relatively high proportions. In the river mouth of Kaidu, Microchironomus dominated mainly following the water dynamics. In the deep area of Bosten lake, Chironomus and Microchironomus show highest abundance.

The RDA analyses revealed that water depth, SD and salinity (Fig. 5) were the predominant factors influencing chironomid distribution in Bosten lake. Water depth is commonly encountered as a significant environmental variable in modern chironomid training datasets (Larocque et al., 2001; Barley et al., 2006; Zhang et al., 2011), and subsequent transfer functions have been developed for the reconstruction of lake water depth (Korhola et al., 2000; Luoto 2009). Water depth may exert an influence on spatial and temporal heterogeneity of chi- ronomids due to its intensive effects on environmental conditions that indirectly influence the midge larvae. Water depth is closely related to water temperature, food availability and oxygen conditions, which could in turn influence the distribution of chironomid communities (Lindegaard, 1995; Korhola et al., 2000).

In the case of Bosten lake, water depth has a strong influence on the distribution of chironomid larvae and many taxa have depth preferences. T. glabrescens-type, C. sylvestris-type, G. barbipes-type, Limnophyes, P. nubifer-type and $P$. sordidellus-type were mainly restricted to relatively shallow regions of the lake (Fig. 5b) and most of these genera are associated with macrophytes (Brodersen et al., 2001; Langdon et al., 2006; GathorneHardy et al., 2007). Meanwhile, Chironomus and Microchironomus were abundant in the deep regions of the lake; these genera are commonly found in the most eutrophic lakes in China, according to previous studies on subfossil chironomids (Zhang et al., 2006, 2010). Furthermore, $C$. plumosus-type individuals have been reported to be capable of surviving in hypoxic conditions as they possess haemoglobin (Little and Smol, 2000).

Relatively low values of salinity were measured primarily near the Kaidu river mouth and there was a northsouth salinity gradient across the lake. Salinity also significantly influences the chironomid distribution in Bosten lake. Several previous studies of subfossil chironomids from different regions have reported the significance

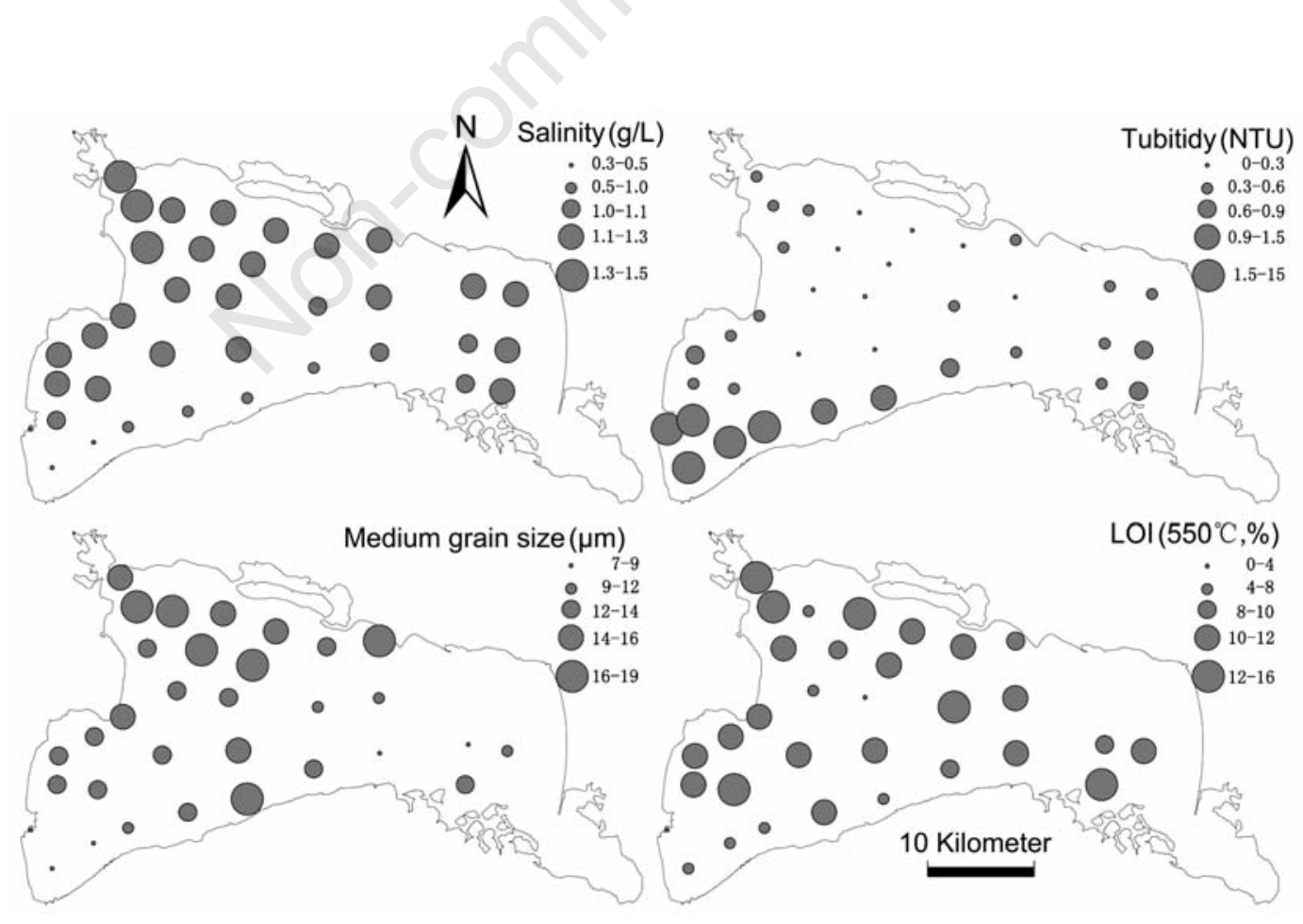

Fig. 2. Gradients of selected environmental parameters in Bosten lake in August 2010. 
of salinity in influencing the distribution and abundance of chironomid assemblages (Heinrichs and Walker, 2006; Eggermont et al., 2006). Even though the salinity gradient in Bosten lake is considerably narrow except for sites near the Kaidu river mouth (Fig. 2), the chironomid taxa show clear changes along the salinity gradient (Fig. 3b). Microchironmus dominated in the area near the Kaidu river mouth, and T. glabrescens-type and C. sylvestris-type were the main taxa in other sites with higher saininty contents (Fig. 3b). Since the 1980s, the salinity of Bosten lake has continually increased (Zhang and $\mathrm{Hu}, 2008$ ); this may have markedly influenced development of the chironomid fauna, and detailed palaeolimnological studies will be needed to discern this. The sites near the Kaidu river mouth have low SD, as many suspended solids are brought into the lake. Water transparency is another key
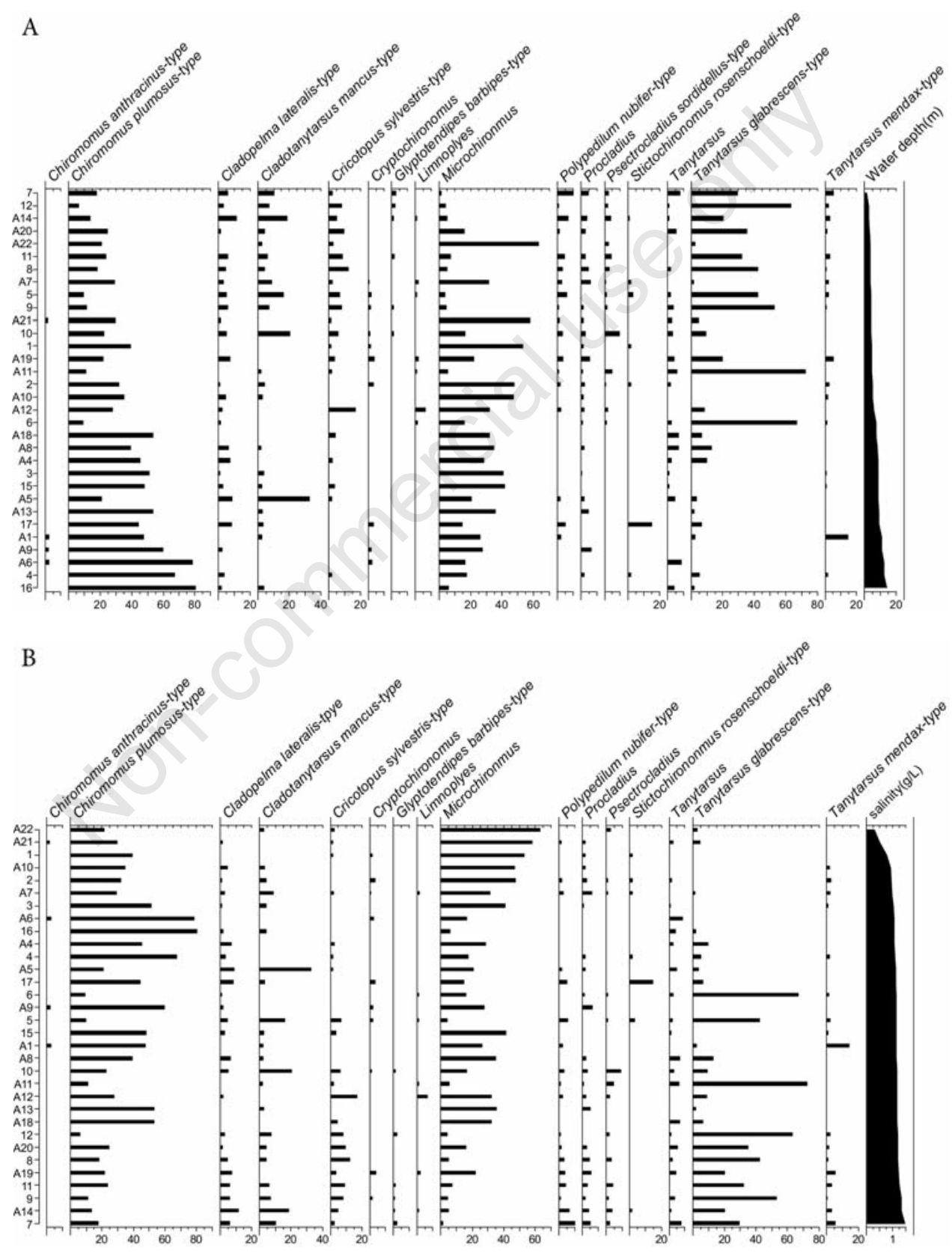

Fig. 3. Percentage of main chironomid taxa in Bosten lake. A) Samples are arranged in ascending order of sample depth; B) Samples are arranged in ascending order of salinity. 

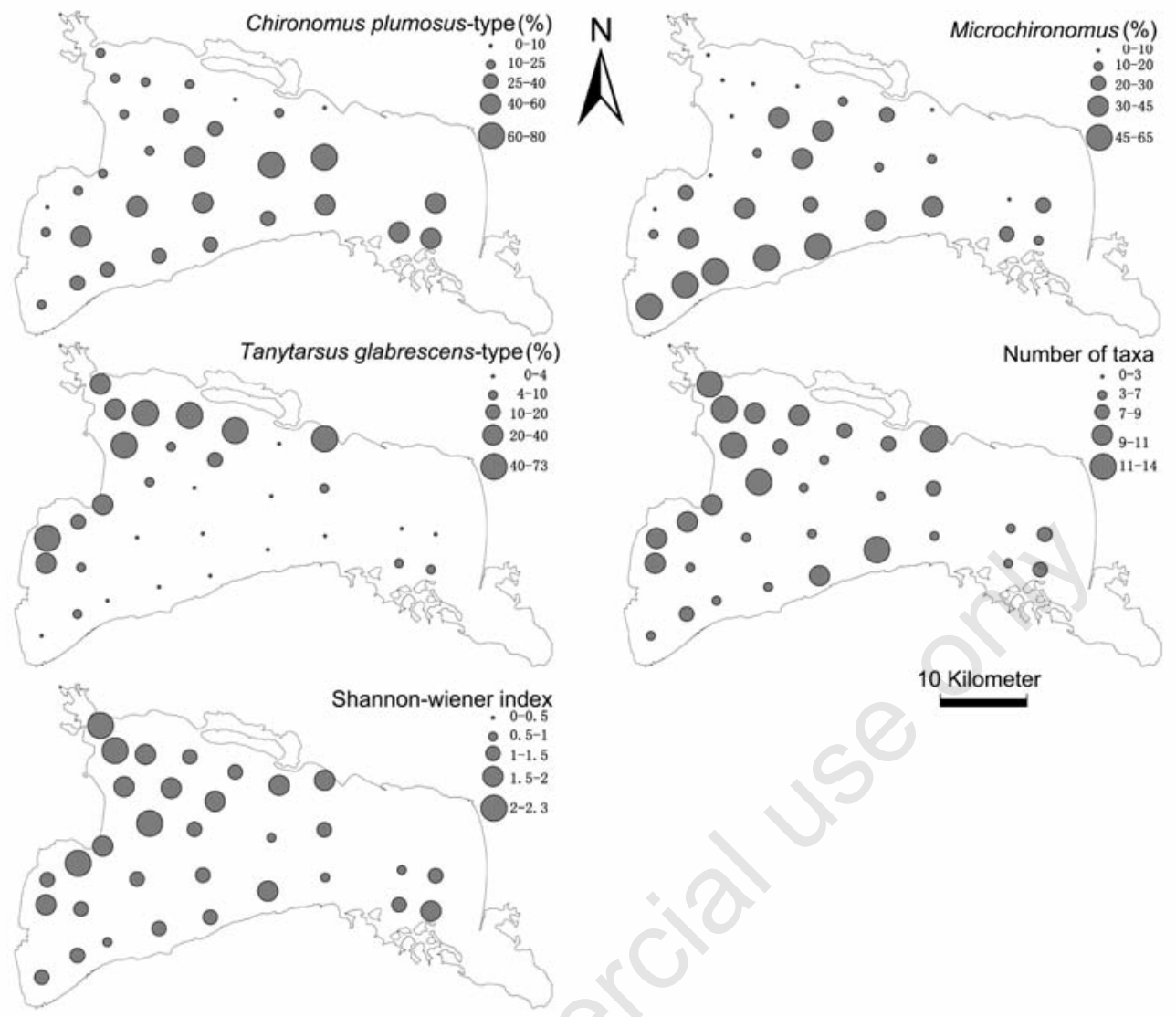

Fig. 4. Percentage abundance of Chironomus plumosus-type, Microchironomus and Tanytarsus in Bosten lake.
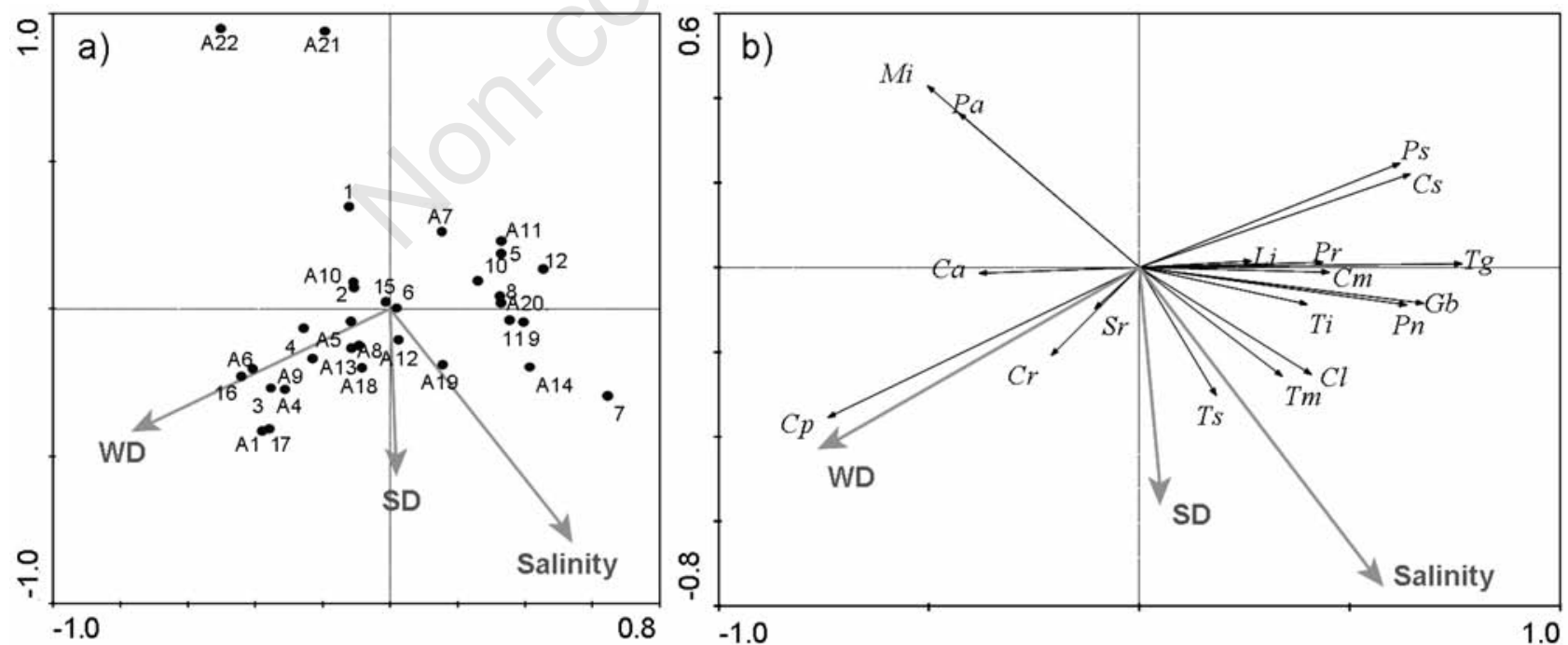

Fig. 5. Redundancy analysis biplots of significant environmental variables: a) samples; b) species within the Bosten lake. Abbreviations of species: Ca, Chironomus anthracinus-type; $\mathrm{Cl}$, Cladopelma lateralis-type; $\mathrm{Cm}$, Cladotanytarsus mancus-type; Cp, Chironomus plumosus-type; Cr, Cryptochironomus; Cs, Cricotopus sylvestris-type; Gb, Glyptotendipes barbipes-type; Li, Limnophyes; Mi, Microchironomus; Pn, Polypedilum nubifer-type; Pr, Procladius; Ps, Psectrocladius sordidellus-type; Sr, Stictochironomus rosenschoelditype; Tg, Tanytarsus glabrescens-type; Ts, Tanytarsus; Tm, Tanytarsus mendax-type. 
factor determining the survival and growth of submerged and leaf-floating plants. The growth of submerged macrophytes is limited when the underwater light climate deteriorates as a result of the increased surface turbidity (Middelboe and Markager, 1997; Vestergaard and SandJensen, 2000), and in turn the development of macroinvertebrates would be hindered due to the lost of their shelter and food source provided by aquatic plants (Jeppesen et al., 1998), especially for those macrophyte-related species (Brodersen et al., 2001; Fig. 5b).

The taxon richness (number of chironomid taxa) decreased along the depth gradient, except the sites in the Kaidu river mouth where diversity was low, suggesting the significant influence of both water depth and water dynamics on the chironomid assemblage. The sites in the Kaidu river mouth area with high water dynamics had higher suspended inorganic partials, lower Loss on ignition (LOI) and lower SD, which maybe exerted the observed impacts on chironomid diversity and richness. The chironomid diversity (Shannon-Wiener index) is low, with an average diversity of 1.52 in the sites, and none of the sites exceeded 2.2 (Fig. 4). A similar pattern was observed between the diversity (Shannon-Wiener index) and species richness of chironomid within Bosten Lake. The sites in the river mouth and in deep water had low diversity, while the Huangshuiwan sites had high diversity. The anomalously low chironomid diversity is also reported from other lakes in China (Zhang et al., 2011), which may be the results of human impact.

Further studies, particularly long-term evaluation of chironomid diversity from lake sediment sequences within China, should be conducted to put our results in wider context.

\section{CONCLUSIONS}

The chironomid community in Bosten lake was mainly dominated by C. plumosus-type, Microchironomus and $T$. glabrescens-type, and their distribution exhibited obvious spatial heterogeneity. The increasing salinity and nutrient level in recent years in Huangshuiwan favoured the development of T. glabrescens-type. In the Kaidu rRiver mouth, Microchironomus mainly dominates regions affected by the water dynamics. C. plumosus-type and Microchironomus are more abundant in the deeper regions of Bosten lake. The relatively low chironomid diversity in the lake probably results from human disturbance and the salinity changes occurring in recent years, as well as the suspended materials and freshwater supplied by Kaidu river.

This first intra-lake subfossil chironomid study from this region will aid the interpretation of palaeolimnological datasets to reconstruct past changes in climate and environmental conditions, and to compare the current human-influenced lentic environment with the previous pre-impact conditions. Additionally, regular monitoring of invertebrates, including living chironomids, should be carried out to provide additional information to detect real changes in ecological structures, which would be convenient to refine the lake management for sustainable development and ensure the lake's necessary ecosystem functioning.

\section{ACKNOWLEDGEMENTS}

The authors are grateful to Dr. Zhijun Gong, Dr. Xiangming Tang and Mr. Kexu Chi for their help on fieldwork, to Mr. Yongbo Wang for his help during the preparation of the manuscript.

This study was supported by the Special Environmental Research Funds for Public Welfare of the State Environmental Protection Administration (grant 200909048), the National Water Pollution Control and Management of Science and Technology Major Projects (grant 2009ZX07106-004) and National Natural Science Foundation of China (41072267).

\section{REFERENCES}

Barley EM, Walker IR, Kurek J, Cwynar LC, Mathewes RW, Gajewski K, Finney BP, 2006. A northwest North American training set: distribution of freshwater midges in relation to air temperature and lake depth. J. Paleolimnol. 36: 295-314.

Brodersen KP, Odgaard BV, Vestergaard O, Anderson NJ, 2001. Chironomid stratigraphy in the shallow and eutrophic Lake Søbygaard, Denmark: chironomid-macrophyte co-occurrence. Freshwater Biol. 46: 253-267.

Brooks SJ, Langdon PG, Heiri O, 2007. The identification and use of Palaearctic Chironomidae larvae in palaeoecology. QRA Technical Guide No. 10, Quaternary Research Association, London.

Chen FH, Huang HZ, Zhang JW, Holmes JA, Chen JH, 2006. Humid little ice age in arid central Asia documented by Bosten Lake, Xinjiang, China. Sci. China Ser. D 49: 12801290.

Cranston PS, 1995. Introduction, p. 1-7. In: P.D. Armitage, P.S. Cranston and L.C.V. Pinder (eds.). The Chironomidae: the biology and ecology of non-biting midges. Chapman and Hall, London.

Eggermont H, Deyne PD, Verschuren D, 2007. Spatial variability of chironomid death assemblages in the surface sediments of a fluctuating tropical lake (Lake Naivasha, Kenya). J. Paleolimnol. 38: 309-328.

Eggermont H, Heiri O, Verschuren D, 2006. Fossil Chironomidae (Insecta: Diptera) as quantitative indicators of past salinity in African lakes. Quaternary Sci. Rev. 25: 1966-1994.

Engels S, Cwynar LC, 2011. Changes in fossil chironomid remains along a depth gradient: evidence for common faunal thresholds within lakes. Hydrobiologia 665: 15-38.

Frey DG, 1988. Littoral and offshore communities of diatoms, cladocerans, and dipterous larvae, and their interpretation in paleolimnology. J. Paleolimnol. 1:179-191.

Gathorne-Hardy FJ, Lawson IT, Church MJ, Brooks SJ, Buchland PC, Edwards KJ, 2007. The Chironomidae of Gróthúsvatn, Sandoy, Faroe Islands: climatic and lake-phosphorus 
reconstructions, and the impact of human settlement. Holocene 17: 1259-1264.

Hall RI, Leavitt PR, Quinlan R, Dixit AS, Smol JP, 1999. Effects of agriculture, urbanization, and climate on water quality in the northern Great Plains. Limnol. Oceanogr. 44: 739-756.

Heinrichs ML, Walker IR, 2006. Fossil midges and palaeosalinity: potential as indicators of hydrological balance and sealevel change. Quaternary Sci. Rev. 25: 1948-1965.

Heiri O, Birks HJB, Brooks SJ, Velle G, Willassen E, 2003. Effects of within-lake variability of fossil assemblages on quantitative chironomid-inferred temperature reconstructions. Palaeogeogr. Palaeocl. 199: 95-106.

Heiri O, Lotter AF, 2001. Effect of low count sums on quantitative environmental reconstructions: an example using subfossil chironomids. J. Paleolimnol. 26: 343-350.

Holmes N, Langdon PG, Caseldine CJ, 2009. Subfossil chironomid variability in surface samples from Icelandic lakes: implications for the production and use of training sets. J. Paleolimnol. 42: 281-295.

Jeppesen E, Søndergaard Ma, Søndergaard Mo, Christofferen $\mathrm{K}, 1998$. The structuring role of submerged macrophytes in lakes. Springer, New York.

Jin HL, Wang XF, Wang Z, Xu YD, Huang FJ, 2002. Study on resources development and environmental protection of the Bosten Lake. [Article in Chinese]. Research of Soil and Water Conservation 9: 58-61.

Korhola A, Olander H, Blom T, 2000. Cladocera and chironomid assemblages as quantitative indicators of water depth in subarctic Fennoscandian lakes. J. Paleolimnol. 24: 43-54.

Kurek J, Cwynar LC, 2009. Effects of within-lake gradients on the distribution of fossil chironomids from maar lakes in western Alaska: implications for environmental reconstructions. Hydrobiologia 623: 37-52.

Langdon PG, Ruiz Z, Brodensen KP, Foster IDL, 2006. Assessing lake eutrophication using chironomids: understanding the nature of community response in different lake types. Freshwater Biol. 51: 562-577.

Langdon PG, Ruiz Z, Wynne SW, Sayer CD, Davidson TA, 2010. Ecological influences on larval chironomid communities in shallow lakes: implications for palaeolimnological interpretations. Freshwater Biol. 55: 531-545.

Laroque I, Hall RI, Grahn E, 2001. Chironomids as indicators of climate change: a 100-lake training set from a subarctic region of northern Sweden (Lapland). J. Paleolimnol. 26: 307-322.

Lindegaard C, 1995. Classification of water-bodies and pollution, p. 385-404. In: P.D. Armitage, P.S. Cranton and L.C.V. Pinder (eds.), The Chironomidae: biology and ecology of non-biting midages. Chapman and Hall, London.

Little JL, Smol JP, 2000. Changes in fossil midge (Chironomidae) assemblages in response to cultural activities in a shallow, polymictic lake. J. Paleolimnol. 23: 207-212.

Liu WX, Zhang JZ, 1998. Investigation of the effect of wastewater from sugar factory on the algae in Bosten lake. [Article in Chinese]. Research of Environmental Sciences 11: 16-19.

Luoto TP, 2009. Hydrobiological change in lakes inferred from midge assemblages through use of an intralake calibration set. Ecol. Monogr. 80: 303-329.

Middelboe AL, Markager S, 1997. Depth limits and minimum light requirements of freshwater macrophytes. Freshwater Biol. 37: 553-568.

Oliver DR, Roussel ME, 1983. The insects and arachnids of Canada. Part II: The genera of larval midges of Canada. Diptera: Chironomidae. Agriculture Canada Publ. 1746, Ottawa: 263 pp.

Quinlan R, Smol JP, 2001. Chironomid-based inference models for estimating end-of-summer hypolimnetic oxygen from south-central Ontario shield lakes. Freshwater Biol. 46: 1529-1551.

Rieradevall M, Brooks SJ, 2001. An identification guide to subfossil Tanypodinae larvae (Insecta: Diptera: Chironomidae) based on cephalic setation. J. Paleolimnol. 25: 81-99.

Saether OA, 1979. Chironomid communities as water quality indicators. Ecography 2: 65-74.

ter Braak CJF, Prentice IC, 1988. A theory of gradient analysis. Adv. Ecol. Res. 18: 271-317.

ter Braak CJF, Šmilauer P, 2002. CANOCO reference manual and CanoDraw for Windows user's guide: software for canonical community ordination (version 4.5). Microcomputer Power, Ithaca, NY.

Tronstad LM, Tronstad BP, Benke AC, 2007. Aerial colonization and growth: rapid invertebrate responses to temporary aquatic habitats in a river floodplain. J. N. Am. Benthol. Soc. 26:460-471.

Vestergaard O, Sand-Jensen K, 2000. Aquatic macrophyte richness in Danish lakes in relation to alkalinity, transparency, and lake area. Can. J. Fish. Aquat. Sci. 57: 2022-2031.

Walker IR, 2001. Midges: Chironomidae and related Diptera. In: J.P Smol, H.J.B Birks and W. Last (eds.), Tracking environmental change using lake sediments. Vol. 4. Zoological indicators. Kluwer, Dordrecht.

Walker IR, Fernando CH, Paterson CG., 1984. The chironomid fauna of four shallow, humic lakes and their representation by subfossil assemblages in the surficial sediments. Hydrobiologia 112: 61-67.

Wang S, Dou H, 1998. Lakes in China. Science Press, Beijing.

Wiederholm T, 1983. Chironomidae of the Holarctic Region. Keys and diagnoses. Part I. Larvae. Entomologica Scandinavica Supplement: $457 \mathrm{pp}$.

Xu HL, Chen YN, Li WH, 2003. Analysis on the pollution situation of Bosten lake. [Article in Chinese]. Journal of Arid Land Resource and Environment 17: 95-97.

Zhang E, Jones R, Bedford A, Langdon PG, Tang H, 2007. A chironomid-based salinity inference model from lakes on the Tibetan Plateau. J. Paleolimnol. 38: 477-491.

Zhang EL, Bedford A, Richard J, Shen J, Wang SM, Tang HQ, 2006. A subfossil chironomid-total phosphorus inference model from the middle and lower reaches of Yangtze River lakes. Chinese Sci. Bull. 51: 2125-2132.

Zhang EL, Langdon P, Tang HQ, Richard J, Yang XD, Shen J, 2011. Ecological influences affecting the distribution of larval chironomid communities in the lakes on Yunnan Plateau, SW China. Fund. Appl. Limnol.179: 103-113.

Zhang EL, Liu EF, Jones R, Langdon P, Yang XD, Shen J, 2010. A 150-year record of recent changes in human activity and eutrophication of Lake Wushan from the middle reach of the Yangtze River, China. J. Limnol. 69: 235-241.

Zhang JP, Hu SX, 2008. Salinity analysis of Bosten lake. [Article in Chinese]. Arid Environmental Monitoring 22: 19-23. 